\title{
More than meets the eye: on the importance of retail cigarette merchandising
}

Richard W Pollay

Tobacco Control 2007;16:270-274. doi: 10.1136/tc.2006.018978

Point-of-sale activity is important enough to get the attention of the senior management of transnational firms and to be the subject of sophisticated research aimed to realise "intrusive visibility" better through creative design, command attention and convey brand imagery. The result of this is the promotional "positioning" of products, and the creation of both friendly familiarity and perceived popularity. The intended results include increased sales of cigarettes as a product or "category growth".

L avack and Toth ${ }^{1}$ called our attention to the importance of point-of-purchase (POP) promotion or retail merchandising, the total cost of which now commands an impressive $85 \%$ of the whopping total of over US\$15 billion spent in promoting cigarettes in the US. Like them, I have reviewed corporate documents in the course of preparing expert opinion for the governments of Canada, ${ }^{2} \mathrm{UK}^{3}$ and Ireland. ${ }^{4} \mathrm{My}$ experience supplements theirs as I reviewed many British American Tobacco (BAT) documents from around the world, and also reviewed the retail merchandising textbook and trade literature. Although not in major disagreement, I fear that Lavack and Toth might leave the erroneous impression that competition for market share is the sole intent and effect of retail promotion. On the contrary, point-of-scale (POS) promotions, like other forms of advertising, are carefully crafted, creatively executed, well-financed, well-researched promotional efforts supervised by senior management and aimed at realising intrusive visibility to convey brand imagery (to the extent allowed) with the goals of enhancing category image and category growth.

\section{DEFINITIONS AND FUNCTIONS OF POS}

POS or POP merchandising displays and signage are clearly a medium of advertising and are explicitly referred to as such in the title of the relevant global trade association, the Point of Purchase Advertising International (POPAI). One text comments that "Displays should accomplish the five steps of selling, just as advertising and personal selling should". The five steps mentioned are as follows: (1) attract attention, (2) arouse interest, (3) create desire, (4) build confidence and (5) direct action. ${ }^{5}$ Industry documents offer similar ideas.

The purposes of POS are multiple. On one level, POS materials are designed to attract attention and to enhance brand images. On another level, they are used to convey the "presence" of the brand to consumers, to create the perceived popularity of brands, and hence of smoking. These serve the ultimate strategic goals of differentiating brands from one another so as to minimise competitive substitution and the associated price competition that squeezes profitability.

The purpose of POS promotion, like other advertising, is to sell, not to convey material information, contrary to common claims in litigation. The functional purposes of POS materials were articulated in one 1979 BAT document: (1) to inform the consumer of the presence of the brand; (2) to promote recognition of the brand; (3) to generate interest and excitement about the brand; and (4) to stimulate trial purchase and re-purchase. ${ }^{6}$ It is noteworthy that the provision of information about the physical properties of the product, its ingredients or the performance characteristics of the brand, much less its risks or probable health consequences, was not an objective of POS marketing.

\section{SENIOR MANAGEMENT ATTENTION AND INTERNATIONAL STANDARDS}

As Lavack and Toth noted, the management of cigarette-selling firms has been spurred to pay closer and closer attention to retail promotion by regulation. In-store activity has been of ever-growing importance since at least 1970, as a consequence of restrictions on other means of promoting sales. For example, BAT took the view in 1970 that a "key sales executive" needed to study merchandising:

[T] he role of merchandising is likely to become increasingly important in the event of ad restrictions, and considerably more attention is, therefore, being given to this activity, both in Millbank and a number of associated companies. ... The main purpose of these activities are ... (c) to create conditions which give an immediate stimulus to purchase at point-ofsale ... It is therefore recommended that a key sales executive should be appointed to study the subject of merchandising ${ }^{7}$

Twenty years later, in 1991, senior BAT executive Paul Bingham stated:

So in a market where no promotion of cigarettes is allowed, you could expect to see the following ... more efficient use of the trade, and in-store communications, i.e. permanent merchandising material and point of sale temporary material (e.g. stickers). The aim is to create a better impact-to let the retail environment communicate the values of the product more effectively. ${ }^{8}$

Note that this refers to the product (cigarettes) not to the brand (eg, Marlboro). Two new transnational positions were created in 1993, presumably within each operating region, in support of in-store marketing: Regional Trade Marketing \& Distribution Manager and Regional Merchandising Manager (see Pedlow, ${ }^{8}$ at 500316641 ).

A multivolume manual was developed in the early 1990s, for the entire global operation of BAT that "selected the best

Abbreviations: BAT, British American Tobacco; ITL, Imperial Tobacco Company Ltd; POP, point of purchase; POS, point of sale; POPAl, Point of Purchase Advertising International, Washington DC, USA 
practices from the field of in-store marketing and applied it to the tobacco industry. It can be used as a tool to train and develop personnel as well as provide guidelines to implement more effective in-store marketing". ${ }^{9}$ The manual consisted of four books covering in-store marketing, merchandising, promotion and providing a catalogue of BAT-approved merchandising. The first three books had "full distribution to all operating companies and field forces" (see BAT, ${ }^{9}$ at 500316629). Despite this wide distribution, to my knowledge, not one of these three books has yet been produced in litigation, even that focused on POS issues.

\section{HIGH-TECH POS RESEARCH}

BAT suggested three types of research to evaluate POS effects, before, during and after an operation, and suggested that measurements and targets could include awareness, trial, brand usage, believability, comprehension, interest, attitudes and over-the-counter sales. ${ }^{10}$ In 1972, BAT felt the need to do its own practical research effort. "Merchandising and promotions. The biggest problem in this area is to measure and assess the effectiveness of merchandising, in terms of cost and obtaining objectives, and this must be a priority area for further work" ${ }^{\prime 1}{ }^{1}$ BAT stated in 1979:

\begin{abstract}
Maximum perceptual recognition should be achieved at point-of-sale by the appropriate pack style and design, by dynamic display layout, and by point-of-sale advertising materials ... All these factors should be the subject of continuous research. To this end, we should seriously consider the merits of setting up experimental in-stores so that, for example, label designs, pack sizes, POS materials, etc. can be evaluated. (see BAT, ${ }^{6}$ p 6)
\end{abstract}

Two very high-tech devices have long been used to research displays by BAT on behalf of its operating companies: (1) a tachistiscope to flash visuals at high speed (short duration) to study how readily displays could be apprehended and (2) an eye gaze camera to monitor eyeball movement when encountering displays. In 1982, BAT's Project Bristol used eye gaze monitoring equipment to study how "consumers visually interact with their environment". The planned analysis included the effects of shop window displays. ${ }^{12}$ In 1986, BAT used a tachistiscope to assess the eye-catching qualities of various designs when amassed. It was judged, in the executive summary, that "... the style of tachistiscopic testing reported here represents a high time/cost effective addition to the process of pack development. It allows the assurance that the various symbolism carried by the pack is achieving the desired effect in terms of impact". ${ }^{13}$

The Psychology Group of BAT's Market Research operation contracted at least 18 months of research on the efficacy of POS, further adapting the eye gaze equipment. "This technique makes use of an eye-gaze monitor to make the measurements and an infra-red technology and computorised [sic] digitization to analyze the results. By examining the routes of tracking over the display the output of the analysis provides a cumulated picture of the visual hot spots on the display. With this information it is possible to better position our brands on the gantry in order to receive the maximum amount of visual attention". Because the technique was complex, this research was conducted by Charter Research Associates, with the aim to produce "a handbook providing guidelines on maximizing the potential of the POS display" for use by all operating companies in diverse jurisdictions. Subjects were drawn from both the UK and the Far East to understand better whether reading styles affected eye patterns while shopping and to help make this relevant to Asian as well as to Western cultures. ${ }^{14}$
Like the merchandising manuals, this research by Charter Research Associates has not yet been located despite considerable effort.

\section{INTRUSIVE VISIBILITY}

BAT stated in 1970:

Tobacco products must be positioned so that they will be easily visible, readily accessible to shop assistants and displayed in such a way as to generate a strong impulse to buy. A special in-store promotion will be most effective if it is positioned so that it can be seen by the customer before he actually reaches it. ... By adjusting shelf-heights and by the use of shelf extenders, shelf-talkers, arrows, etc., it is possible to make facings stand out to give additional impact. ... Directional arrows, day-glow material, flashes, stars and similar eye-catching methods can be used to attract the attention of specific brands or temporary offers. ... With these and other aids, the trained merchandiser can bring an additional attraction quickly and cheaply to his product situated in a market stall, vending machine or in the tobacco department of a large supermarket ... Pictures and slogans should be kept to a minimum and be placed near the product but designed to be clearly visible at a distance from which the customers will normally view it. ${ }^{15}$

Similarly, Philip Morris stated in 1991:

Key Point: We should have Marlboro (and other PM brands) positioned in the store to take advantage of the impulse shopper. ... Where are the best spots for promotional offers, POS, etc.? We are after intrusive visibility. ${ }^{16}$

Similarly:

'Eye Level is Buy Level' because items placed at eye level are more likely to be purchased that those on higher or lower shelves. ... Place posters in line with the main customer flow into the shop. Look for uncluttered locations to gain maximum visual impact for the poster. Place posters at eye level. In-shop, position posters in main traffic flow from point of entry to point of purchase or place in uncluttered position near point-of-purchase or place material above eye level if it can be seen at a distance. ${ }^{10}$

\section{CREATIVE DESIGN}

Modes or types of POS advertising include banners, displays, posters, easels, shelf signs, streamers, wall units, window displays and cards, floor stands, dump bins, counter-top units, illuminated signs, cash register tools (eg, change trays, customer merchandise dividers, receipt coupons and message imprints), shopping carts and baskets, end-of-aisle displays, racks, gantries, kiosks, overhead hangers, price cards, interactive units, aisle directories, waste baskets, mechanical product dispensers, ashtrays, closed circuit television and radio broadcasts, electronic scrolling ads, clocks, "hours open" signage, carpets and floor mats, laser projections onto floors and walls, oversized mock-ups of packets, newspaper and magazine racks, etc. New computer and projection technologies are being employed to create displays with interactivity, customisation of messaging, dynamic and vivid illuminated images. For another example, see the video monitors at the ready in fig 1. 


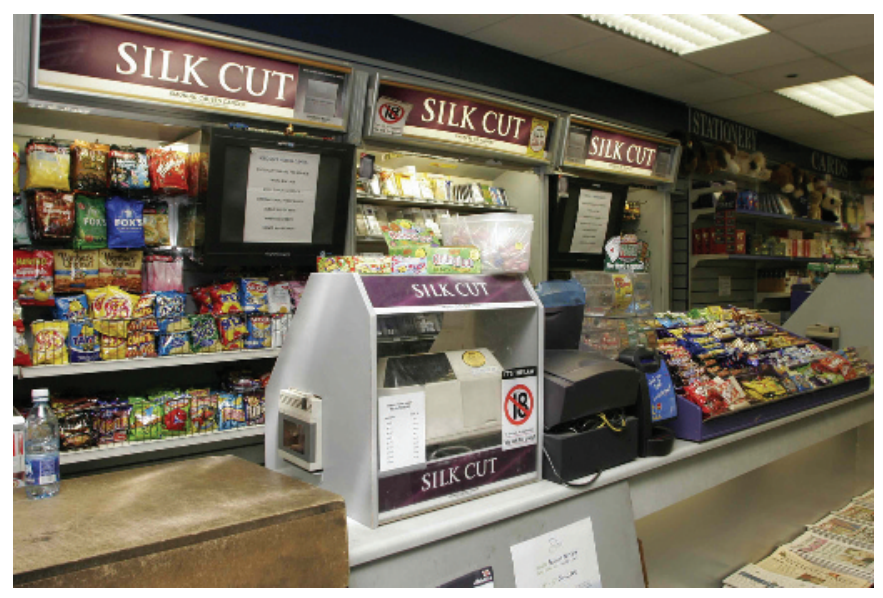

Figure 1 Intrusive visibility. Cash register in an unneeded branded box, repeated back lit overhead signage, and two video terminals provided by the tobacco firm. (Ireland 2006)

The creation of advertising within regulatory restraints can serve as a goad to creativity. Prohibitions and limitations "should not be allowed to discourage the cigarette advertiser, but rather exhilarate him to be able to meet the new confining conditions (of 1972) more effectively than one's competitors is a challenge to creativity and ingenuity". ${ }^{17}$ In 1998 , shortly after the signing of the US Master Settlement Agreement, "RJR provided elegant display racks for Camel, Winston and Doral brands, while B\&W splurged on displays for Kool and Lucky Strike, including an elaborate guitar wall display for Lucky Strike". ${ }^{18}$ In 1999, POPAI awarded its "Permanent Display of the Year" award to RJ Reynolds Tobacco for its Camel trade store program. ${ }^{19}$ New eye-catching technologies are also employed, such as the translucent cigarette packs with lightning dancing inside used by BAT's American subsidiary, Brown \& Williamson, for their Kool brand. This "lightning pack" display won Kool an Outstanding Merchandising Achievement Award from the Point of Purchase Institute. ${ }^{20}$ The new "Power Walls" in Canada contain a diversity of design elements as seen in fig 2.

\section{CONVEYING BRAND IMAGERY}

With ever more regulations, "agreements" and voluntary restrictions on conventional forms of tobacco advertising, "The biggest promotion issue becomes how to build image

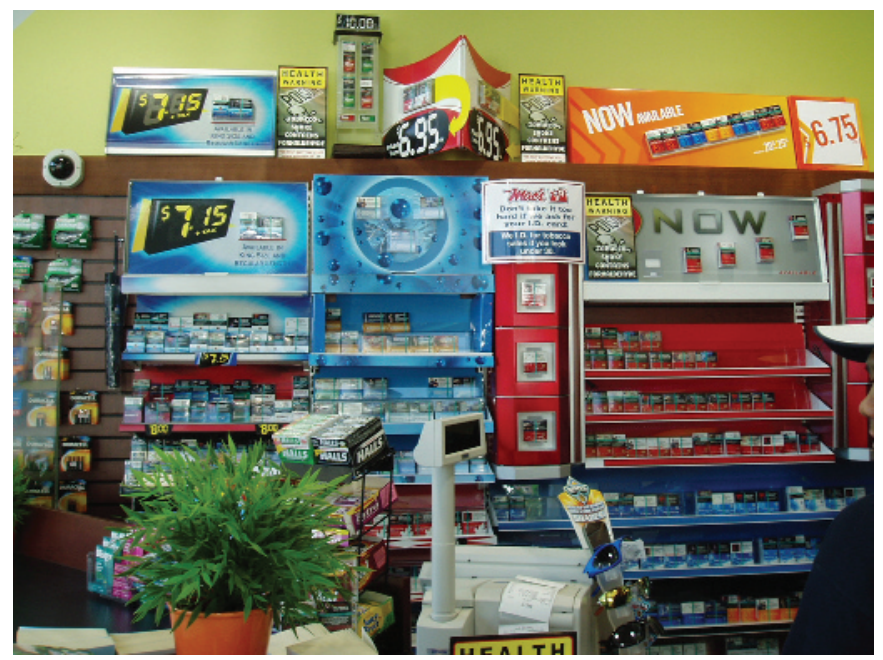

Figure 2 The new "power walls" in Canada displaying a diversity of design elements. with little more than tombstone ads. It is the biggest marketing dilemma of the century, and the solution will be on-premise promotion, coupled with highly targeted direct marketing". ${ }^{18}$

In Canada, POS materials were developed in the 1990s by most major brands to convey their brand imagery. The 1996 Communication Plans for the Player's brand specified that "merchandising must reflect youthfulness and be contemporary", and was recognised as having the ability to "aid in the development of a highly image-driven campaign". ${ }^{21}$ Historically, the brand image was more fully described as "youthful self-expression of freedom and independence and self-reliance/inner confidence" ${ }^{22}$ Similarly, the Belvedere brand was positioned as "youthful, fun, informal, casual, modern and sociable". ${ }^{23}$ Therefore, the "Belvedere merchandising 'look' should communicate its desired positioning elements as young, fun, informal and sociable". ${ }^{24}$ Imperial Tobacco Company Ltd's Plans for Matinee in 1997 called for merchandising activities "to reflect the desired imagery" with communication that "reinforces the trademark's attributes (modernity, popularity) and maintain current perception of femininity, mildness as well as communicating self-indulgence and relaxation". ${ }^{25}$

Canadian marketing documents, authored while the federal legislation tightened controls on media advertising, show that retail activities sought to use fonts, colours, graphic elements and display design to convey various brand images or brand personality traits, such as classy, elegant, fashionable, informal, sociable, young, fun, distinctive, international, modern, contemporary, high tech, a "wellness" product, masculine, macho, independent and rugged.

The BAT Global Policy was to use POS materials to "strengthen brand image". The entire in-store efforts of BAT were governed by the global standards for consistency and quality in message, signage and brand representation. These standards were to ensure that all BAT efforts around the globe "must reflect, add to and strengthen the brand's image" (see $\mathrm{BAT}^{9}{ }^{\mathrm{p}} \mathrm{p} 1.13$ or 500316640$)$.

\section{PRESENCE AND PERCEIVED POPULARITY}

In 1986, Imperial Tobacco, BAT's Canadian operation in Montreal, Quebec, initiated Project HARPO, almost certainly named after the mute Marx Brother. No complete research report for this effort has yet been located, but Project HARPO anticipated regulatory restrictions that "would virtually eliminate our traditional means of expressing lifestyle positioning", as well as the possibility of "the loss of conventional image material in all media (retail included).... [T] hese interventions would severely impede our ability ... to influence market presence and perceived popularity". ${ }^{26}$

Subsequently, ITL felt that "popularity will take on an even larger role than it has today and the job of communicating it will be located almost exclusively in the retail environment." ${ }^{27}$ By 1992, it was noted that "regulatory imposition has also affected the retail environment. By the end of next year, all brand/trademark imagery communication will be disallowed. Consequently, the role of the store as image carrier will change substantially. In future, the store's most vital function will be generating presence" ${ }^{\prime 2}{ }^{28}$

\section{CATEGORY GROWTH}

The POPAI official textbook states: Point-of-purchase promotions have been found to have a significant influence on consumer shopping behavior..". After gaining understanding of consumers, "point-of-purchase professionals can then exploit these consumer decision processes and increase product category or brand sales". ${ }^{29}$

The historical role of marketing was to offer "support of smokers and the smoking habit, and try, at least, to maintain the 


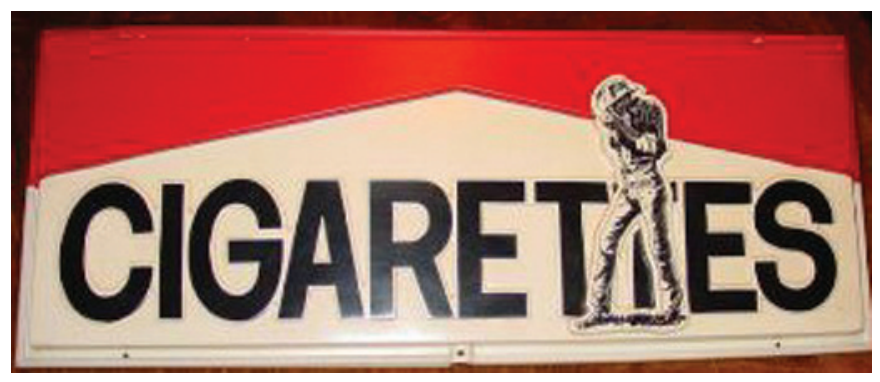

Figure 3 Conveying brand image using only brand element. Obviously promoting Marlboro though not babelled as such.

incidence of smokers in the population, as well as increase daily consumption". In the conclusion to this document, the following goal is reiterated:

The marketing perspective should be broadened ... specifically towards maintaining the smoking habit at current levels, and if possible to increase those levels. We should not rest content with the traditional role of marketing, which aims to increase market share. ${ }^{30}$

The stated objective of BAT's global policy and practice standards for retail activity circa 1993 includes: "To achieve longterm dependable growth of the category and our brands. Use of innovative in-store marketing techniques by trade channels will help achieve our growth objectives" (see BAT, ${ }^{9}$ p 1.10). Later POS communication is stated as yielding enhanced brand image and enhanced "category image" and "category growth" - that is, cigarettes as a group look more appealing and more are sold as a result ( see BAT, ${ }^{9}$ p 1.29).

\section{DISCUSSION}

Given the regulation of cigarette advertising in conventional media, cigarette marketing strategy has been paying more and more attention to retailing or POS merchandising. Given its importance and the resources at their disposal, this attention has involved senior management, international coordination and substantial sophisticated research efforts. This has resulted in deploying creative displays, with very substantial budgets spent to buy the continuing cooperation of retailers.

The fact that the retailers are being handsomely paid should not be overlooked. The fact that they need to be paid strongly suggests that the size and nature of the displays and signage that the tobacco firms seek to install are more substantial than the retailers' natural inclination without this financial inducement. This indicates that the racks, gantries and other dispensing equipment are more than what retailers find necessary to handle the logistics of inventory and dispensing. It also suggests that the displays and signage are more than the retailers would normally deploy, given the sales volume and profit margins.

This heavy spending could be the result of indisciplined competitive spending. The difficulty with this explanation is that tobacco is definitely not an indisciplined industry. Also, this sort of heavy spending and massive displays occurs even in markets dominated by one or a few firms characterised by gentlemen's agreements, if not outright collusion. The heavy spending on retail displays by a monopoly or oligopoly is understandable as an investment, however, if this spending assists in the recruitment of new smokers, the future of the industry.

Because consumers use the retail presence as an indicator of how popular products are, a substantial oversized display conveys that many people are smokers. This is in addition to whatever else might be conveyed regarding special offers, pricing, brand imagery, etc. This perceived popularity effect occurs at the brand level, as consumers discern which brands are the more popular. It also occurs at the product level, as consumers discern the popularity of cigarettes by their centrality and predominance in the retail milieu. This perceived popularity effect would occur even if all firms (for the sake of argument) had only market share intentions for their spending on displays.

Note, also, that this perceived popularity effect and its contribution to the total category sales occur even if regulation restricts the ability of firms to convey brand imagery, but do not otherwise restrict their retail presence. It is constructive to restrict the conveyance of brand imagery in POS advertising, as in other media, lest cigarettes be romanticised and made particularly appealing, but doing only this may be insufficient, however necessary. Similarly, regulation that does not restrict the use of brand elements will be relatively ineffective, even if brand names are banned, as can be seen in fig 3 .

\section{CONCLUSIONS}

On the basis of the additional corporate documents and additional trade literature that I have reviewed, I conclude that retail POS merchandising within the tobacco industry has the following traits.

Well researched and financed: Trade research undertakings, while only partially documented, appear to be very sophisticated efforts, designed to create POS materials that are successful in attracting attention and conveying brand imagery. The manufacturing of these items, and their deployment in the retail trade, is fully supported financially.

Crafting brand images, not conveying information: Transmission of information is rarely the objective of marketing plans for tobacco, even incidentally, while establishing a noticeable presence and conveying brand imagery is almost universally the prime objective. The only exceptions are for brands wanting their low prices to be noticed. POS materials do not yield betterinformed consumers.

Intended to reassure and recruit: Tobacco/cigarette advertising, by apparently both intent and consequences, has the function of simultaneously reassuring existing smokers, lest they quit, and recruiting new smokers to start. Recruitment of youth as new smokers is enhanced by POS materials because children are exposed to cigarette promotion throughout their young lives with each and every store visit.

With intrusive visibility: If left unregulated, tobacco merchandising in the retail environment may be vivid in design and intense in density, as the retail venue then becomes the primary advertising medium for the tobacco industry. Firms can seek, can well afford and are readily able to obtain the needed cooperation from retailers. Both design and deployment and retail POS signage make it prominent to the point where it is highly likely to be noticed by a very high proportion of store customers.

Creating perceived popularity: The resulting presence has the intention and effect of influencing perceived popularity. This perceived popularity effect is true for individual brands, and consequently for the product category of cigarettes as a whole. Thus, in addition to whatever might be communicated about the differentiated character of various brands, the size and volume of retail display creates a message to the entire retail traffic-that is to both smokers and non-smokers-about the popularity of cigarette smoking. Beyond this, specific brand images may also convey that smoking is glamorous, part of the good life, enjoyed by people of social status, etc.

POS has enormous reach: A proliferation of POS advertising activity may reach a very large fraction of the population, 


\section{What this paper adds}

- Supplementing Lavack and Toth (TC, 2006), this paper provides documentary evidence that retail promotions intend to increase total cigarette sales, not just market share for competing brands. This is the result of extensive sophisticated research and well-funded creative efforts conveying brand images (to the extent regulations allow) and the creation of perceived popularity.

essentially everyone who goes to market. It would expose all shoppers, regardless of age and smoking status, to what are easily seen as pro-smoking messages and imagery.

POS yields high frequency: Average consumers would be exposed to these messages repeatedly, every time they shop, whether through repeat visits to neighbourhood stores or even if shopping around at various retail establishments. This would be many, many times a year at the least, and for some people many times a week.

Shaping perceptions: In-store advertising materials serve the same functions as traditional advertising materials: the crafted shaping of perceptions, attitudes and beliefs about the brands within a product category, and hence inevitably about the product category itself. Attitudes will change as a function of mere exposure to branded communications even if these are nominally without substantive content, because of the "friendly familiarity" effect.

In sum: POP advertising exposes and potentially affects everyone: the young who grow up seeing tobacco as a benign cultural commonplace in the market on a par with milk and bread and come to underestimate its risks; the adult smoker who is reminded and cued to smoke now and more often; the occasional smoker who is cued to consume more; the would-be quitter whose intentions to quit are undermined; and the exsmoker tempted to relapse and resume smoking. Regulation of both the amount (size) and character (brand imagery) of POS advertising is, therefore, a legitimate and important component of the tobacco control strategy, with substantial potential for advancing public health, particularly in jurisdictions where it is the predominant mode of sale promotion.

\section{EPILOGUE: TOBACCO FIRMS DROP POS CASE AGAINST IRELAND}

On 31 January 2007, with the trial imminent, the legal challenge to the Public Health (Tobacco) Acts, 2002 and 2004, in Ireland, put forth by a number of tobacco companies and others, was discontinued, at their request, with all costs awarded to the State. This sudden abandonment of the litigation challenge to legislation, knowing the evidence like the above that the judge would see, probably reflected their judgement that victory was very unlikely and that a loss might set an international example. The Irish Office of Tobacco Control can now focus on getting gantries taken out of shops, POS advertising for cigarettes and tobacco products removed, and tobacco products placed in sealed containers and out of view of customers. In their view, this is the most significant development in tobacco control in Ireland since the introduction of the smoke-free workplaces legislation.

Competing interests: I am a university business school scholar and have been called often to testify in tobacco litigation to educate judges and juries in several countries as to the firms' marketing practices and the history thereof.

This research was undertaken while preparing expert reports for the federal governments of Canada, the United Kingdom and Ireland.

Correspondence to: Professor R W Pollay, Sauder School of Business, UBC, Vancouver, BC, Canada V6T 1Z2; pollay@sauder.ubc.ca

Received 17 October 2006

Accepted 7 February 2007

\section{REFERENCES}

1 Lavack AM, Toth G. Tobacco point-of-purchase promotion: examining tobacco industry documents. Tob Control 2006;15:377-84.

2 Pollay RW. Point of Sale (POS) advertising of cigarettes: functions, management and consequences. History of advertising archives working paper 4. 5 (Nov 2004); Sauder School of Business, University of British Columbia: 80 pages + and appendices prepared for the Ministry of Health, Canada).

3 Pollay RW. Witness statement of Richard Warren Pollay (re: Point of Sale Advertising). BAT et al v. Secretary of State for Health (UK), High Court of Justice, Queen's Bench Division, History of Advertising Archives Working Paper 4. 2 (July 2004), Sauder School of Business, University of British Columbia, 56.

4 Pollay RW. Witness statement of Prof. Richard Warren Pollay re: Point of Sale Advertising of Tobacco, a supplemental report on corporate documents, trade sources and current practices in Ireland. PJ Carroll v. Ireland, July 2006:30 pages+exhibits.

5 Samson HE, WG Little. Visual merchandising: planning and technique, Vol 3. Place: Southwestern, 1985.

6 BAT. Guidelines on communications restrictions and new opportunities in marketing. Jesteburg May 1979: 5, http://www.library.ucsf.edu/tobacco/ batco/html/14100/14109 (accessed 5 Apr 2007).

7 BAT. Product communication in the context of varying degrees of advertising restriction: 7. http://www.library.ucsf.edu/tobacco/batco/html/13700/13752 (accessed 5 Apr 2007).

8 Pedlow G. Marketing of cigarettes in countries with total Ad bans: notes on conversation with Paul Bingham, 1991.http://www.library.ucsf.edu/tobacco/ batco/html/13200/13217 (accessed 5 Apr 2007).

9 BAT. In-store marketing Manual, nd ( 1993). http://tobaccodocuments.org/ health_canada/50031662.html (accessed 19 Apr 2007).

10 BAT. Merchandising, undated. Appendix 2: xv-xvi, Bates 4061 14627-8.http:// www.library.ucsf.edu/tobacco/batco/html/100/109 (accessed 5 Apr 2007).

11 BAT. BAT International Marketing Conference, Vol 12.Montreal, June 1972.Marketing News Supplement No.18; http://www.library.ucsf.edu/ tobacco/batco/html/13700/13710 (accessed 5 Apr 2007).

12 England Grosse Associates (for BAT). Project Bristol: Eye Gaze Monitoring Study; London: England Associates, year: 1-2. http://www.library.ucsf.edu/ tobacco.batco/html/12700/12739. (accessed 28 June 2007).

13 Miller L. Principles of measurement of visual standout in pack design, BAT Report No.RD 2039. 1986: 3-4, http:/www.library.ucsf.edu/tobacco.batco/html/ 500/511. (accessed 28 June 2007).

14 BAT. A cross cultural comparison of visual scanning patterns: 1. http, / www. library.ucsf.edu/tobacco.batco/html/6700/6755. (accessed 28 June 2007).

15 BAT. Some guidelines for marketing tobacco products in the context of increasing restrictions on advertising, iii-v.

16 Phillip Morris. Marlboro Medium - reference guide, May, 1991:37.

17 BAT. International Marketing Conference, Montreal, June 1972. Marketing News Suppl No. 18, Sep 1972: 11-12, http://www.library.ucsf.edu/tobacco/batco/ html/13700/13710 (accessed 5 Apr 2007).

18 Spethmann B. When the smoke clears. PROMO/Jul, 1998:2.

19 Donovan RJ, Jancey J, Jones S. Tobacco point of sale advertising increases positive brand user imagery. Tob Control 2002;11:191.

20 Liljenwall R, ed. The power of point-of-purchase advertising:marketing at retail.Vol 124. Washington, DC: POPAl, 2004

21 JPB-29. 1996 Communication plans, (ITL-066):33915

22 D-222. ITL-marketing plan, 1989;(ITL-431):22844.

23 RF-20; RBH-1131. Strategic marketing plans, Nov, 1994:39736.

24 RF-45; RBH-1128. Marketing plans 1993/94, 41295.

25 JPB-44. 1997 communication plans, (ITL-065):34676.

26 Project HARPO (memo). Nov 1986, within 9900327.pdf at 400929618-20 (parenthetical in original).

27 D-222. ITL-marketing plan, 1989;(ITL-431):22824-5.

28 P-49 Broad Strokes Plan 1992:5421.

29 Ogden JR, DT Ogden. Consumer behavior at the point of purchase. In: Liljenwall R, eds. The power of point-of-purchase advertising:marketing at retail. Washington, DC: POPAl, 2004:26-9.

30 Kalhok Al, Short PL. The effect of restrictions on current marketing and marketing in the future. BAT Report. 1976: 24, at p9, 14 (emphasis added), http:// www. library.ucsf.edu/tobacco/batco/html/14100/14107 (accessed 5 Apr 2007). 